\title{
HAGIA UNA NUEVA ETICA DEL CORAJE: UN GUAPO DE 900 DE SAMUEL EICHELBAUM
}

\author{
Laura Rosana Scarano \\ Universidad Nacional de Mar Del Plata
}

\section{RESUMO}

Un guapo de 900 é uma das peças dramáticas latinoamericanas que melhor tesemunha a transição de uma cosmovisão estética-naturalista para outra de claro cunho existencialista, onde o individuo consegue romper os condicionamentos deterministas e indagar sobre o sentido de sua vida e ser mais íntimo.

Este artigo se propōe a delinear brevemente o itinerário existencial do protagonista e sua progressiva transformação ao longo da obra, definida tanto por seus díálogos e apariçōes em cena como também por suas significativas auséncias e, de modo definidor, pela relaçāo conflitiva estabelecida com seus antepassados. Assim, é possível ver como evolui de uma concepção rio-platense do "guapo" como mero executor da vontade de seu caudilho, sem outro código que o de uma cadeia arbitrária de honra e submissão, para novos valores baseados na dignidade in. dividual e na assunção reflexiva da própria liberdade.

Esta pieza de 1940 se encuadra dentro de la renovación del teatro del periodo de entreguerras y del cambio de las condiciones históricas, sociales y económicas que generará un nuevo modelo de desarrollo en los países hispanoamericanos. En cuanto a la innovación en la producción dramática y el espectáculo teatral, Eichelbaum pertenece a un sector decididamente partidario de un "teatro de arte", que sustituya a los intereses puramente comerciales de sus predecesores. No es posible ignorar este dato, ya que la pieza que trataremos se inscribe en una linea de teatro psicológico y filosofico que reconoce lecturas europeas (Lenormand, Ibsen, Dostoievski, Strindberg, etc) y que a sua vez reela- 
bora $^{1}$. Sin embargo, el autor no reniega totalmente del viejo teatro rioplatense y recrea en esta pieza los tipos costumbristas que poblaban los escenarios del sainete criollo.

La pieza aparece planteada como un intento de reconstrucción histórica: de un tiempo y de un espacio estilizados por la distancia y la memoria, el 900 rioplatense urbano. Pero tales coordenadas no son más que la excusa para reconstruir un tipo histórico - el del guapo - y reelaborarlo otorgándole una dimensión arquetipica compleja, ya que al dotarlo de dinamismo existencial y evolución psicológica, Eichelbaum destruye el arquetipo entendido como entidad fija e inmutable y lo sustituye por el carácter, paradigmático y ejemplar, pero humano y perfectible.

El tipo del guapo (con numerosos antecedentes en el escenario rioplatense desde Juan Moreira) tiene dos perfiles: uno histórico, como personaje plebeyo, antisocial e indeseable, de personalidad primitiva e instintiva, con rasgos de "compadrón"2, quien presta sus servicios a un caudillo político de turno y "le gana" las elecciones "a punta de cuchillo". $Y$ el perfil mitico con dimensión heroica, tan frecuente en la literatura argentina de esta época (los guapos de Borges, por ejemplo, y otros), asentado en dos sistemas inalterables: "la ética del coraje", presente en la obra a través de actitudes y expresiones de los personajes ${ }^{3}$, y "el código de honor", basado en la subordinación de la libertad individual a un valor considerado superior: la lealtad, que a su vez exige y genera lealtad del caudilo al que sirve.

En la obra, Ecuménico López encarna este perfil mítico del guapo. Don Alejo Garay es el caudillo político al que el guapo sirve. Ladislao, hermano de Ecuménico, es otro guapo de su mismo coraje, pero deliberadamente puesto en segundo plano para no opacar la figura central. Pancho, el tercer hermano, representa al anti-guapo, llamado "hombre como quien dice con enaguas" ( $p .649$ ), alejado de sua familia, nunca en primeira escena, pero de referencia constante, y cuya función será importante (por contraste) en el desarrollo psicológico de la pieza. Natividad López, la madre, encarna (paradojalmente por su condición de mujer) el perfil his-

1 Bobre las Influenclas literarlas, rer CRUZ. J. Samuel Eichelbaum. Buenos Alres. Ed. Culturales Arzentinas. 1962. p. 21.

2 CRUZ. D. 69.

3 EICHEIBAUM. B. Un grupo del 900. In: LUZURIAOA, G. \& REEVE. R. Los clasicon del teatro hispanoamericano. Mexlco. Fondo de Cultura Económlca, 1975. p. 615. Todas las cltas pertenecen a esta edición.

4 Pancho es el único hilo que. desde el punta de rista psicolófico, se presenta liberado del tutelaje materno: su comportamiento no siguo el patrón Impuesto del cuapo, y es el únlco de los tres hermanos que aparece repetidas veces vinculado sentimentalemnte con una mujer, Luclana. lluminando por oposieion la aparente incapacidad afectiva de Ecuménico y Ladisiso. 
tórico y tipificado del guapo: antisocial, borracha, violenta, sin escrúpulos, niega su sexo y se erige como el modelo obligado de comportamiento para sus hijos:

Natividad: (...) Yo no me arrepiento ni por mí, ni por mis muchachos, que han sido siempre como yo he querido que fuesen. Su coraje no lo han robao. En estos pechos resecos se han amamantao... (...) Conmigo tenés que cuidarte, porque la des. gracia de ser poco hombre se te puede doblar cuando te convenzás, además, de que yo soy poco mujer... (p.637).

La pieza presentará el conflicto de identidad de Ecuménico (explícito en las últimas escenas de la obra), que lo enfrentará con la búsqueda de su verdadero ser de guapo, apoyado en una nueva lealtad y un nuevo sistema de valores que privilegie la libertad a la obediencia servil, la verdad a la mentira, la fidelidad a sí mismo y la justicia a la sujeción a un código externo y arbitrario. Estos serán los términos en que se debatirá, y el proceso está presentado implícitamente a través de las sucesivas ausencias y apariciones del personaje en la escena.

La obra consta de tres actos y está dividida en seis cuadros. El primer cuadro del I Acto es costumbrista y presenta a Ecuménico y su madre dentro del espectro de tipos característicos. La relación entre ambos es de clara dominación por parte de la madre, ante la negativa de Ecuménico a que ella siga bebiendo, la madre "le da un sopapo" y le grita "iTe voy a enseñar quién es el guapo aquí!" (p.616). Ella impone el modelo de comportamiento que su hijo ejecuta y pone en acto. Desde el punto de vista psicológico, la madre representa el polo masculino y reprime la autonomía psíquica y existencial de su hijo, manteniéndolo sujeto a ella, subordinado y empequeñecido; con la aparente pasividad de Ecuménico, quien no se atreve a enfrentarse a su madre y romper este vinculo.

El segundo cuadro presenta el conflicto que movilizará al personaje en busca de su libertad: la traición de la mujer de don Alejo, Edelmira Carranza, con un nuevo y joven político, el doctor Clemente Ordónez. Esta situación compromete la dignidad de guapo de Ecuménico, su código de honor y lealtad con don Alejo. Pues, en principio, la verguienza y degradación del caudillo recaen sobre su guapo, y, en segundo lugar, la pasividad ante esa situación de deshonra del caudillo, significaría un acto de traición del guapo. Ecuménico 
se ve forzado por su propio sistema de valores a romper esa cadena de deshonras: decide darle un escarmiento al doctor Ordónez y a la esposa infiel, pero "la fuerza de las circunstancias" lo llevan a matarlo. Este asesinato esta visto como un acto de coraje, justificado por la ética de la lealtad, y así lo razona y explica el mismo personaje:

Ecuménico: (. . ) Soy hombre de don Alejo desde hace muchos años. Usté lo sabe. $Y$ como le cuido la espalda tengo que ver las traiciones que se le hacen y castigarlas a mi modo. No voy nada en el asunto $(\ldots)$. No me obliga más que la lealtá. (p.620)

En el primer cuadro del Acto II Ecuménico se enfrenta con don Alejo y vemos que su código de honor permanece inalterable. La razón del homicidio queda sellada en sus labios y se abandona a la lógica de las acciones aceptando ser denunciado, ya que su lealtad a don Alejo lo ampara y le garantiza una retribución, liberándolo de la prisión. El siguiente cuadro completa la fisonomia del guapo, ubicando a Natividad en una esquina de suburbio. Este ambiente de arrabal y tango tiene una neta función costumbrista, pero además nos da datos de Ecuménico (in absentia): ha sido acusado de homicidio, ya lleva meses en la cárcel, don Alejo aparece como traidor a su guapo.

En el primer cuadro del Acto III, doña Natividad le reclama a don Alejo su "deber de lealtad" y lo amenaza: "Tengo coraje pa' castigar a cualquier felón que traiciona a su más lial servidor" (p.642).

El último cuadro de la obra pone en escena nuevamente a Ecuménico con su madre, y se produce la iluminación del hijo, el reconocimiento consciente y explícito de su transformación. Ha pasado cuatro meses en la cárcel y el resultado de esa "clausura" y aislamiento es el descubrimiento de su auténtica identidad de guapo, basada en una nueva escala de valores. En principio se da el reconocimiento de la culpa: de acuerdo al antiguo código,, el crimen habia sido justificado en términos de lealtad, pero ahora resulta injustificable y se transforma en delito. Al admitir esa culpa Ecuménico admite la responsabilidad que le cabe en sus propios actos y necesita una expiación: “. . . ando ahura con una muerte que tengo que pagar". (p.652). Esto significa entregarse a la justicia legal y exterior, renegando de la anterior justicia del cuchillo y la componenda: “. . . pasao mañana me presentaré a la po- 
licia pa' darme preso! Aqui estoy. Yo he matao al doctor Ordónez. Hagan lo que quieran". (p.652).

Este nuevo código implica además un nuevo concepto de libertad. El antiguo guapo reconocía una libertad voluntaria, pero que una vez entregada al caudillo era condicionada por la lealtad como valor superior: "A mí nadie me manda matar (...). Soy asesino, si le parece, pero por mi voluntá (...). No me obliga más que la lealtá" (p. 620), y "... siempre lhe hecho las cosas por mi cuenta. Me he jugao siempre solo". (p.629). A estas afirmaciones Ecuménico opone al final de la pieza otras con un nuevo concepto de libertad: "Pero isi yo he matao vieja! No quiero una libertá que me esté quemando los pies dondequiera que ande". (p.653). El nuevo Ecuménico reniega de esa libertad falsa porque ha descubierto otra libertad, la que nace de la asunción del propio ser, en la verdad y en la justicia: "(Ecuménico a su madre): Es inútil. Usté no comprende. ¿No ve que me achica la vida? Encerrao, aunque fuera para siempre, no hay hombre que se me iguale, en coraje, en lialtá, en honradez". (p.653). Paradojalmente, la prisión significa para él el acceso a la verdadera libertad, el descubrimiento de otro guapo y de otra ética del coraje, basada esta en la honradez y ya no en la ciega lealtad.

Este aprendizaje existencial que realiza el personaje a lo largo de la obra está jalonado por progresivos cortes con las correspondientes figuras parentales: don Alejo que representa la protección paterna, y Natividad, la madre, en un vínculo psicofisiológico. La asunción de la libertad final se corresponde con la liberación de Ecuménico del tutelaje materno en la ültima escena, cuando impone su decisión, se autorreconoce como distinto y se separa psíquica, ideológica y existencialmente de su madre. De acuerdo al código determinista anterior, "los hijos no tienen otro recurso que cum. plir con un destino que existe independientemente de sus voluntades, que los domina y avasalla", pero Ecuménico "pone en tela de juicio ese destino y la necesidad de su cumplimiento"s. Su liberación también comienza con la independencia del tutelaje de don Alejo a partir de la pérdida del respeto, que significa la destrucción del paradigma del caudillo, con una disminución de su hombría: "Me distancié de don Alejo (...). Me pareció que un hombre no puede servir a otro emporcao por una mujer". (p.653). El alejamiento se acentúa y en la escena de enfrentamiento con don Alejo, Ecuménico preanuncia su posterior transformación: "Toy relajao de tanto andar en macanas (...). Una pelea brava

3 ROJO. G. Los orígenes del teatro hispanoamericano contemporáneo. Valparaiso. Ed. Universitarias de valparafso, 1972. p. 126. 
puede lavarlo a uno de tanta porquería que yeva adentro" (p.628). Este reconocimiento se hace explícito al admitir Ecuménico, en la última escena, su dualismo interior: "Y no sé quién, que estaba siempre a mis espaldas, me decía: ¿No ves que es un castrao?" (p.653).

La liberación total da paso al renacimiento del ser, oportunamente ubicado por el autor en la víspera del Año nuevo, en la tradicional celebración del fin y acabamiento del ser pasado, para el surgimiento y nacimiento del ser futuro. La dualidad se resuelve en el fortalecimiento del yo autónomo del personaje, quien ya no se definirá como "el guapo de don Alejo" o "el hijo de Natividad López"; ya no necesita de un caudillo a quien servir ni de una madre a quien obedecer para definirse ontológicamente: ha encontrado la justificación de su existencia en sí mismo, y eso le basta.

La resolución de la pieza indica claramente la ruptura de Eichelbaum con los determinismos histórico-sociales y biológicos del teatro que lo precedió, ya que el énfasis está puesto en las posibilidades de autodeterminación de los personajes, que los ayudan a sobreponerse a los condicionamientos de la conducta, transformando la pieza en un proceso de "revelaciones continuas" del movimiento espiritual interior del ser humano".

\section{REFERENCIAS BIBLIOGRAFICAS}

1 CRUZ, J. Samuel Eichelbaum. Buenos Aires, Ed. Culturales Argentinas, 1962.

2 LUZURIAGA, G. \& REEVE, R. Los clasicos del teatro hispanoamericano. Mexico, Fondo de Cultura Económica, 1975.

3 ROJO, G. Los origenes del teatro hispanoamericano contemporâneo. Valparaíso, Ed. Universitarias de Valparaiso, 1972.

6 Aliredo de la Guardia define a los dramas de Elchelmaum como "teatro de lo inconsclente" (CRUz. p. 25) y ROJO define esta novedad como la ruptura del personaje plano "con um solo rostro o por lo menos con un solo rostro 'real' contrastado con lá indole siempre camblante de sus postbles ficetones" (p. 133).

T Entre las motivaclones que lo lleran a Etehelbaum a eseribir esta obra está la fascinación por el "suapo puro". el deseo de indagar ia esencia del mito popular ("el resorte (ntimo por el chal aciua" con palabras de Elchelbaum) $J$. fundamentaimente. el interés por demostrar el sentido ético de la llbertad como valor supremo de la existencla humsna. 